\title{
Effects of Vehicle Restriction Policies on Urban Travel Demand Change from a Built Environment Perspective
}

\author{
Xiaoyun Cheng, ${ }^{1}$ Kun Huang, ${ }^{1}$ Lei Qu, ${ }^{1}$ Tianbao Zhang, ${ }^{2}$ and Li Li $\mathbb{D}^{3}$ \\ ${ }^{1}$ College of Transportation Engineering, Chang'an University, Xi'an 710064, China \\ ${ }^{2}$ School of Software Engineering, University of Science and Technology of China, Suzhou 215123, China \\ ${ }^{3}$ School of Electronics \& Control Engineering, Chang'an University, Xi'an 710064, China \\ Correspondence should be addressed to Li Li; lili@chd.edu.cn
}

Received 24 December 2019; Revised 22 June 2020; Accepted 2 July 2020; Published 17 July 2020

Academic Editor: Shamsunnahar Yasmin

Copyright (c) 2020 Xiaoyun Cheng et al. This is an open access article distributed under the Creative Commons Attribution License, which permits unrestricted use, distribution, and reproduction in any medium, provided the original work is properly cited.

\begin{abstract}
License plate restriction (LPR) policy presents the most straightforward way to reduce road traffic and emissions worldwide. However, in practice, it has aroused great controversy. This policy broke the original structure of the urban transportation mode, which needed some matching strategies to adapt to this change. Investigating this travel demand change is a challenging task because it is greatly influenced by features of the local built environment. Fourteen variables from four dimensions, location, landuse diversity, distance to transit, and street design, are used to depict the built environment; moreover, the severe collinearity underlies these feature variables. To solve the multicollinearity among the variables and high-dimensional problem, this study utilizes two different penalization-based regression models, the LASSO (least absolute shrinkage and selection operator) and Elastic Net regression algorithms, to achieve the variable selection and explore the impacts of the built environment on the change of travel demand triggered by the LPR policy. Travel demand changes are assessed by the relative variation in taxi ridership in each traffic analysis zone based on the taxi GPS data. Built environment variables are measured using the transportation network data and the Baidu Map Service points of interest (POI) data. The results show that regions with a higher level of public transportation service and a higher degree of the land mix have a stronger resilience to the vehicle restriction policy. Besides, the contribution rate of public transportation is stable as a whole, while the contribution rate of richness depends on specific types of land use. The conclusions in this study can provide in-depth insights into the influence of the LPR policy and underpin traffic complementary policies to ensure the effectiveness of LPR.
\end{abstract}

\section{Introduction}

In the past several decades, the drastic growth of private car ownership and usage has caused some vexing problems, such as traffic congestion and environmental pollution $[1,2]$. Cars are indisputably an important contribution to photochemical smog pollution [3]. To improve the urban living environment, many cities have attempted to implement various traffic demand management (TDM) policies [4] to mitigate these problems. These strategies can be divided by purpose into two categories: (1) the control of private car ownership from the source through the license plate lottery or license plate auction policies implemented in Beijing, Shanghai, and Guangzhou [5] and (2) the reduction of private car usage through congestion pricing [6] and license plate restriction (LPR) policies. For years, LPR policies have been implemented in several cities worldwide, like South America (Bogota) [7] and Mexico City, the most populous city in North America [8]. Some cities with serious "urban disease" caused by air pollution have adopted joint countermeasures. For instance, Beijing implemented a combination of the license plate lottery and LPR policies.

The LPR policy, also called road space rationing is the most straightforward way to reduce road traffic and emissions by limiting vehicle access to a road network based on the last digits of the license number on preestablished days. The one-day-per-week (ODPW) vehicle restriction policy does exactly what its name implies by forcing private 
vehicles off the road "one day per week." A more stringent policy, the odd-and-even (OAE) policy, only permits vehicles to get on the road alternately based on the odd or even status of the last digit on their license plates. As implemented in Delhi, these two LPR policies are effective in the daytime on weekdays, and the following vehicles are exempted: all taxis and buses as well as cars operating on compressed natural gas (CNG) and electric power [9]. In practice, the OAE policy is usually taken as a "first-aid treatment" or a contingency plan [10] for special events or, during an occurrence of serious air pollution, to quickly reduce traffic volume, which was implemented in Beijing during the Olympic Games in 2008 [11-14] and when Xi'an and Langfang suffered severe air pollution [10]. Up to now, more than 10 cities in China have employed the ODPW policy as a routine TDM strategy and the number will increase with rapid motorization in further.

However, in practice, the LPR policy has aroused great controversy and public ire [15]. It was found by managers and researchers that this policy was only effective in mitigating congestion and air pollution over a short period and the longterm effect has fallen short of expectations [16]. The numerical results also confirm the unintended consequences of LPR in many practical cases [17]. This is mainly because the LPR policies may not effectively make commuters transfer from restricted private car usage to public transit [18]. Conversely, such policies could stimulate purchasing a second car [18] and result in more second-hand car usage [19]. These measures used to evade the LPR policy exacerbate traffic congestions and air pollution and consume more parking spaces to accommodate the extra vehicles. Except for increasing the commuters' acceptance of the LPR policy [16] from a subjective dimension, the primary goal of traffic managers today is to strategize how to guide LPR restricted travel demands towards a higher usage rate of public transit via external policy, because the built environment would affect residents' behavior and change their social and economic activities [20]. Similarly, when the residents' private vehicles are restricted, the choice of alternative modes of travel is directly influenced by the built environment. The following considers the impacts of the built environment on travel mode changes under the LPR policy.

Three important issues need to be addressed when implementing the LPR policy: (1) What are the spatial characteristics of demand change caused by the LPR policy? (2) How does the built environment influence this demand change in different regions? (3) What targeted policies and strategies should urban and transportation managers take to adapt to changes in travel demand?

Despite the rich studies scrutinizing the social and traffic effects of the vehicle restriction policy, related research is rarely reported on the travel demand change under the context of the LPR policy. This is partly because existing research is more focused on the effect of LPR policies on traffic congestion $[9,13]$ and air pollution mitigation [21]. However, the main obstacles are a lack of panel data to reflect citywide demand changes and an appropriate model to portray the complex relationship between the built environment and demand change.
To fill the gap, this paper explores the built environment effect on the traffic mode transfer within the LPR policy context, leveraging taxi GPS trajectory data, because a taxi can provide a travel experience similar to that of the door-todoor service with a private car, and the change in taxi ridership can effectively reflect the transfer inclination. To achieve this work, two penalization-based regression models are employed to implement the variable selection of all built environment factors, since it allows the collinearity between variables. Then, we utilize Wilcoxon's signed-rank test to scrutinize the regions with significant variation in travel demand.

The remainder of this paper is organized as follows. The next section presents a literature review on the LPR policy and the relationship between the built environment and taxi ridership. Section 3 introduces the data and variables. Section 4 presents the modeling approach. Section 5 presents the results. The final section highlights the key findings and offers implications for traffic demand management.

\section{Literature Review}

In the past decade, an unforeseen increase in private car ownership and usage [21] has caused severe traffic and environmental problems. The most direct and impactful TDM strategy, the license plate restriction (LPR) policy, has been widely implemented in major Chinese cities. A large number of researches on the effectiveness of that vehicle restriction policy and others have led to positive and negative findings, including urban traffic condition improvements [22-24], air pollution mitigation [22-24], safety efficacies [25], and acceptance and reactions of travelers [15], as well as illegal travel $[8,9,14,26]$.

Reducing urban air pollution and the traffic congestion was the original intention of the urban managers and policymakers who initiated the LPR policy. However, previous works related to the effects of all the vehicle restriction policy show an insignificant impact on air quality [23, 27]. Moreover, the long-run effectiveness of this policy will be weakened by vehicular volume adjustments [28] and the possibility of atmospheric chemistry that can reduce NO but elevate $\mathrm{NO}_{2}, \mathrm{NOx}$, and $\mathrm{O}_{3}$ [29]. The direct effect of this policy on traffic conditions is evident to travelers and has been verified by researchers using various quantitative indicators and methods. Several studies have affirmed the LPR policy's reduction in traffic volume [11-13, 30], which naturally leads to a reduction in traffic congestion [28]. Some studies investigated that the LPR policy led to a rise in travel speed based on the citywide records of the travel speed level [27] and the microwave detectors [13], respectively. Moreover, different levels of effectiveness were also explored between two typical license-plate-number-based vehicle restriction strategies, that is, ODPW and OAE. Mohan et al. [9] found the odd-even day traffic restriction policy forced a traffic demand shift from private vehicles to public transport. Liu et al. [10] compared these two policies from travel demand and traffic condition perspectives based on the massive license plate recognition (LPR) data in Langfang, China. They found the policy shift from ODPW to OAE 
significantly reduced the traffic volume and improved the travel speed in most of the road segments, in both peak hours and off-peak hours. But the effect was not as significant as expected due to the increase of illegal travel $[14,26]$ and antipolicy measures such as purchasing a second car [18], nor did the OAE substantially improve the control of traffic demand [31]. Therefore, Jia et al. [16] indicated that promoting the public's acceptance is a vital prerequisite for implementing the LPR policy. Only the traffic demand shifts from private vehicles to public transport ensure the longterm effectiveness of the vehicle restriction policy $[9,12]$. Thus, quantifying the demand change and understanding its determinants are important to realize the mode shift triggered by the vehicle restriction policy.

Unfortunately, studies referring to exploring the spatial characteristic of the mode shift and its relationship with the built environment under the LPR policy are still lacking. Enormous literature has confirmed the critical role of the built environment on transit ridership [32,33]. However, the issue of how restricted travel demands transfer among the different modes under different built environments has been largely neglected in the past years. This is essential for the manager and policy-makers to underpin or support complementary policies used to reduce residents' beneficial losses (giving up unmanaged car use for a healthier environment) to the utmost extent. Moreover, Çetin and Yasin Er [34] found the transferred demand relies only on the taxi, a complement for other public transport modes. However, few researchers have attempted to investigate the potential problems of public transportation from the taxi standpoint. Therefore, it is necessary to explicitly reexamine the influence of the current built environment on the mode shift under the vehicle restriction policy from the perspective of taxi ridership.

\section{Study Area and Data}

3.1. Study Area. Serious fog and haze events have frequently occurred during the autumn and winter months in Xi'an, China [35]. Residents have been suffering a high level of atmospheric particulate matter (PM2.5 and PM10) and various health problems $[36,37]$. Therefore, the ODPW policy was first initiated for this designated region on November 4 in 2016 by the Xi'an Environmental Protection Bureau and Municipal Transportation Bureau to reduce vehicle emissions. The ODPW policy was in effect during weekdays from 7:00 a.m. to 8:00 p.m. except on weekends. Specifically, this strategy restricted vehicles based on the two last digits of the license plates each day, and all new energy vehicles and public transport vehicles, such as taxi and bus, were not affected by this policy. Since the original intention of this policy is alleviating air pollution, the implementation program has not been routinized and depended on the air pollution degree during November. The detailed restricted days and the corresponding last digits are listed in Table 1.

We chose the main urban area of Xi'an within the scope of the LPR policy implementation as the study area of this research, as shown in Figure 1. We adopted the officially defined traffic analysis zones (TAZs) as the spatial units to
TABLE 1: The ODPW policy implementation in November 2016 in Xi'an.

\begin{tabular}{lcccccc}
\hline Mon. & Tue. & Wed. & Thu. & Fri. & Sat. & Sun. \\
\hline & 1 & 2 & 3 & $\mathbf{4}$ & 5 & 6 \\
7 & - & - & - & $\mathbf{( 4 , 9 )}$ & - & - \\
- & 8 & 9 & 10 & 11 & 12 & 13 \\
14 & - & - & - & - & - & - \\
- & $\mathbf{1 5}$ & $\mathbf{1 6}$ & $\mathbf{1 7}$ & $\mathbf{1 8}$ & 19 & 20 \\
$\mathbf{2 1}$ & $\mathbf{( 0 , 5 )}$ & $\mathbf{( 1 , 6 )}$ & $\mathbf{( 2 , 7 )}$ & $\mathbf{( 3 , 8 )}$ & - & - \\
$\mathbf{( 1 , 6 )}$ & 22 & 23 & 24 & 25 & 26 & 27 \\
28 & $\mathbf{2 9}$ & - & - & - & - & - \\
- & $\mathbf{( 4 , 9 )}$ & $\mathbf{( 0 , 5 )}$ & & & & \\
\hline
\end{tabular}

Note. The symbol "-_" represents no restricted day. The bold values denote the date of license plate restriction and its corresponding last digits.

examine the built-environment effects on the spatial change of the taxi demand. TAZ is a basic geographic unit adaptive to transportation analysis; thus, the study area included 698 TAZs, and the dependent and explanatory variables were calculated for each TAZ.

The primary purpose of this paper is to explain the spatial change of travel demand led by the vehicle restriction policy. We chose two consecutive restricted and unrestricted weeks and used data from 10 weekdays to eliminate the interference of other factors in the results, such as changes in the regional population and car ownership. Sociodemographic characteristics can be considered static in a short time. Notably, another important factor that can greatly affect the results is the trip purpose. Some elastic demands, such as shopping, entertainment, and tourism, can be possibly changed or canceled once the private vehicles were forced off the road. So this study focused on the travel demand during the morning peak, i.e., from 7:00 to 9:00 a.m., as the travel plan of the commuting demand cannot be adjusted arbitrarily and has to choose an alternative traffic mode.

3.2. Data. The GPS-equipped taxi that is floating throughout the city is a suitable proxy of the detector used to investigate the actual effects of the LPR policy on the demand change. The taxi GPS data recorded the trajectories of about 11,555 urban taxicabs running across the city of Xi'an, which created about 21 million log records. Here the fleet size of the taxi did not change during the observation period. Each GPS record contains information of taxi ID, epoch time, position, velocity, and status ( 0 for vacancy and 1 for occupation) with a 30-second sampling interval. From the status, one can easily know if the taxi is occupied by the passenger or not at each trajectory sampling point.

The number of taxi trips was observed to be fairly consistent every week except for external intervention [38] and exhibited reproducible patterns within weeks [39]. To depict the change induced by the external factors, we compared the daily ridership of two unrestricted weeks (blue lines) and a restricted week (orange line), as shown in Figure 2. Here, for retrieving the ridership data from GPS records, one can refer to $[38,40,41]$. We can intuitively see the evident increase resulting from the vehicle restriction 


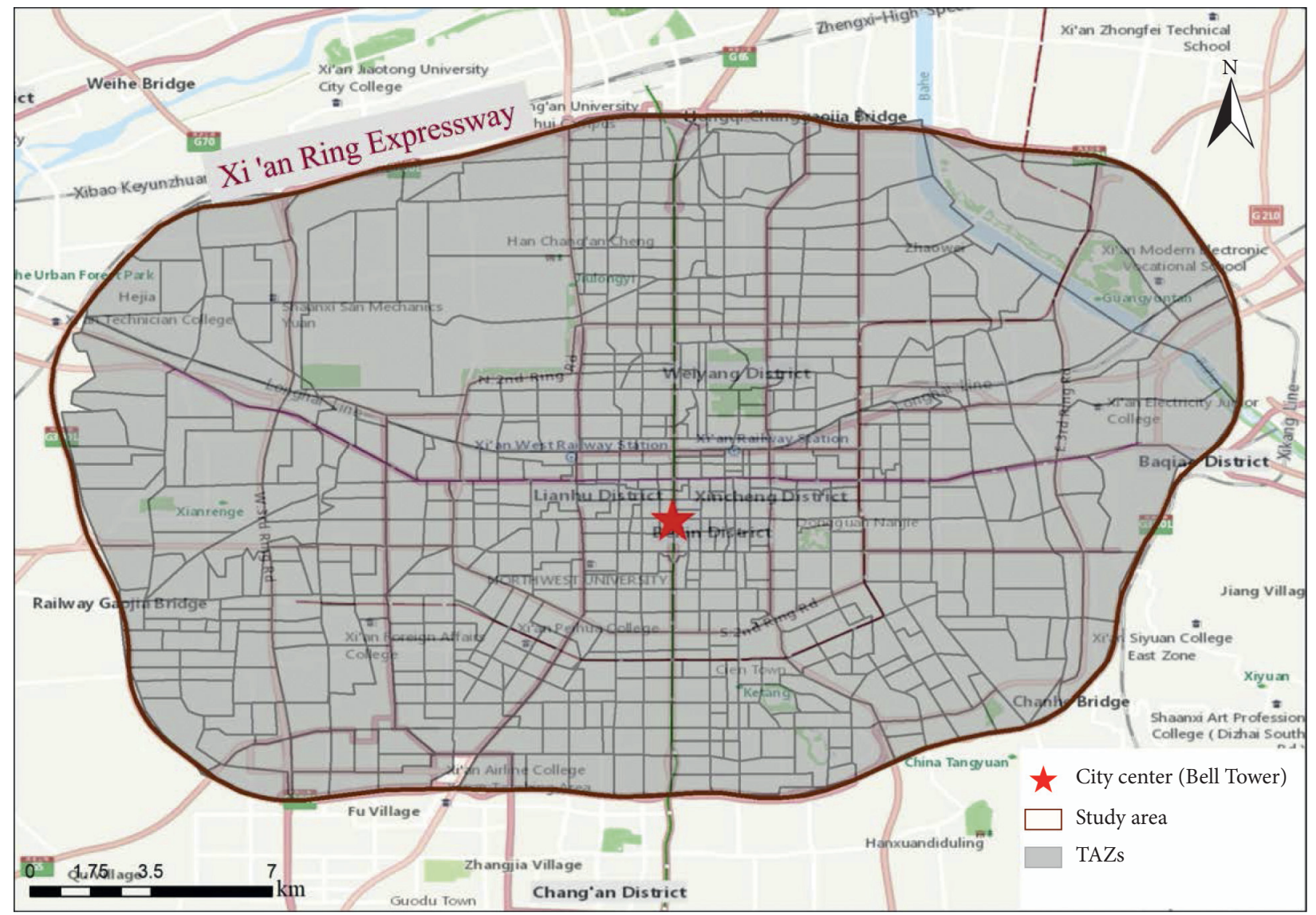

Figure 1: Vehicle restriction areas and study areas.

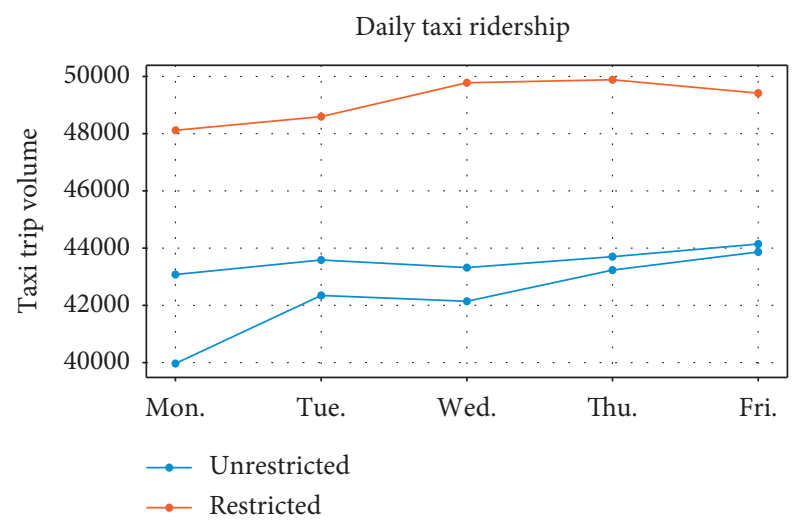

FIGURE 2: Daily taxi ridership in 10 consecutive weekdays.

policy. This illustrates that, on the whole, taxi ridership during the morning rush hour was relatively stable within a certain length of the observation period, and the vehicle restriction policy forced some of the travel demand to transfer to the taxi.

To investigate the variation in effects of LPR with time, we illustrated the taxi ridership at the morning peak for these consecutive three weeks, as shown in Figure 3. The ridership did not show a significant change on the first day of the ban, because most residents knew nothing or adopt a wait-andsee attitude towards this new policy. Therefore, the data collected on this first day could not be used in the final analysis.

3.2.1. Relative Variation in Daily Taxi Ridership: Dependent Variable. We further investigate the local variation of taxi ridership in a fine-grained spatial perspective. The relative variation $(\mathrm{RV})$ in ridership is used to measure the change of travel demand after the vehicle restriction policy and can eliminate the magnitude effects. The relative variation in each TAZ is calculated as shown in equation (1). Based on the ArcGIS platform, we visualized the different relative variations in TAZs adopting different colors, as shown in Figure 4. Blue stands for the decreased area and red for the increased area. The darker the color, the greater the change:

$$
\mathrm{RV}_{i}=\frac{\bar{v}_{\mathrm{after}, i}-\bar{v}_{\text {before }, i}}{\bar{v}_{\text {before }, i}},
$$

where $\mathrm{RV}_{i}$ denotes the relative variation in taxi ridership in the $i$ th TAZ. $\bar{v}_{\text {after } i}$ denotes the average taxi ridership after the vehicles restriction policy and $\bar{v}_{\text {before, } i}$ denotes the average taxi ridership before the policy implementation in the $i$ th TAZ.

Figure 4 shows the vehicle restriction policy has different effects in different regions. Even in two adjacent TAZs, the directions of this influence, i.e., the signs of the relative variation, may be completely opposite. Another result is 


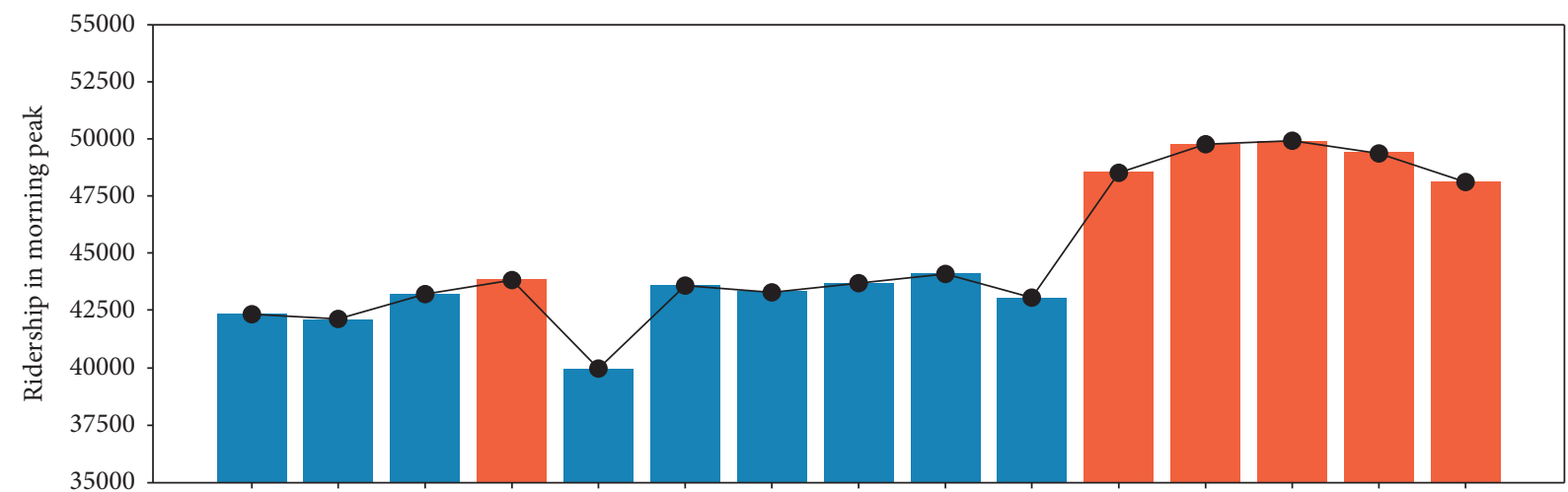

01Tue. 02Wed. 03Thu. 04Fri. 07Mon. 08Tue. 09Wed. 10Thu. 11Fri. 14Mon. 15Tue. 16Wed. 17Thu. 18Fri. 21Mon. Data
- Taxi ridership
Unrestricted
Restricted

FIgURE 3: Time variations in taxi ridership under LPR policy.

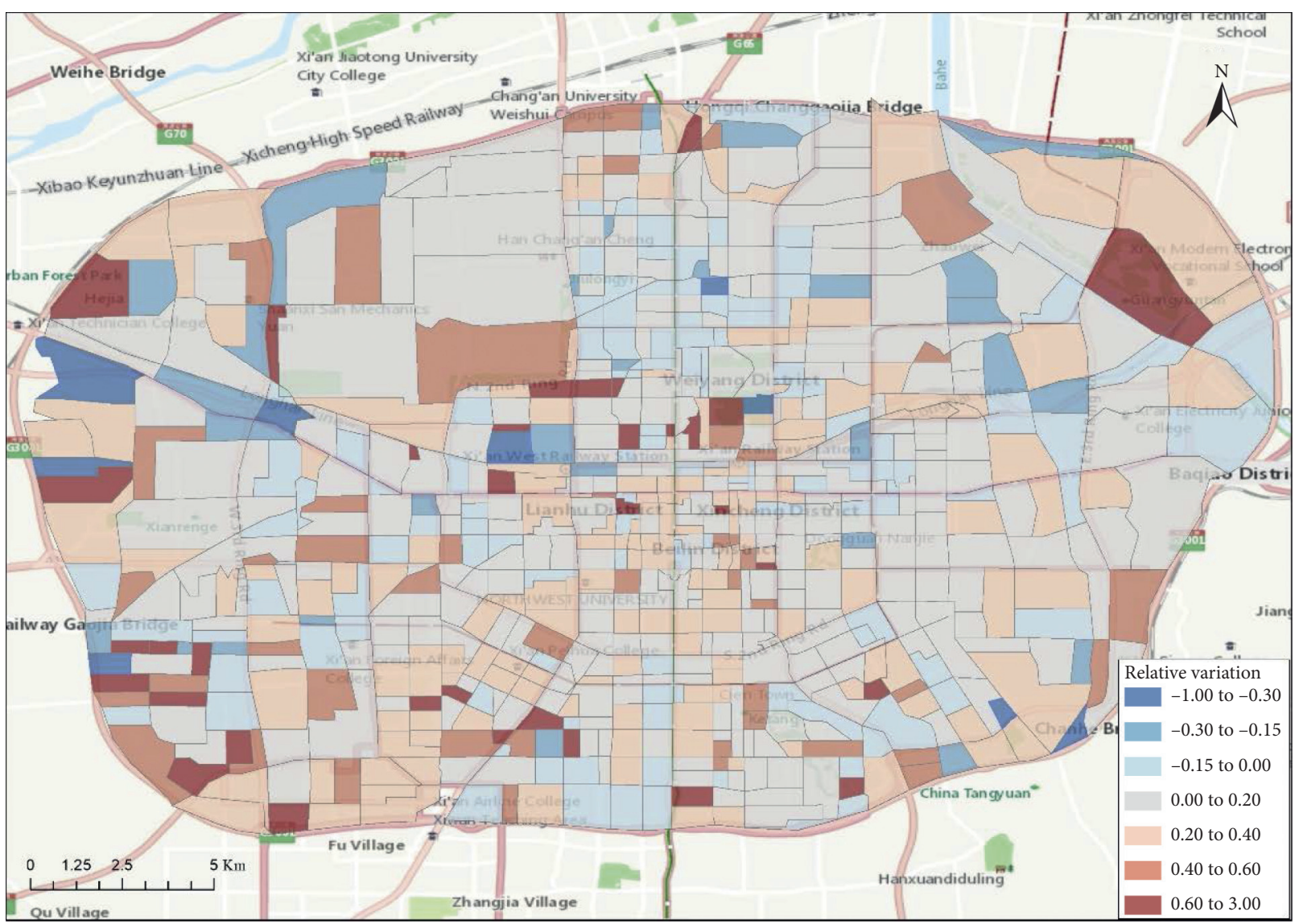

FIgURE 4: The relative variation of taxi ridership in TAZs.

drawn from the spatial distribution perspective; that is, the number of TAZs with the increased ridership is more than that with the decreased ridership in the southwest. Most TAZs have a decreasing tendency in the north. This complex impact of the vehicle restriction policy on the spatial variation of ridership is mainly caused by the built environment.
Consequently, we attempt to explain these different effects from the built environment perspective.

3.2.2. Built Environment: Explanatory Variables. We employed ArcGIS to develop built environment measures for each TAZ, leveraging the Baidu Map Service points of 
interest (POI) data, road network, and public transport network data. The built environment in this study is fully portrayed by 14 variables from location, land mix (diversity), distance to public transportation, and street design dimensions [42]. Notably, the density variables of population and employment are also very important for explaining the demand change, but these variables are not introduced here due to the inaccessibility of the most recent demographics. This lack of more recent data is due to the lack of a current citywide census, which is conducted every 10 years in most cities in China. The description and descriptive statistics of the 14 attribute variables used in this study are presented in Table 2. The location characteristic is represented by the distance from the centroid of the TAZ to the most important urban landmarks. Distance to the city center (Bell Tower) and distance to the nearest local central business districts (CBDs) are always key factors in assessing commuting behavior $[27,43,44]$. These two indicators were estimated using the Euclidian distance. Since the estimation accuracy of land use using POIs is higher than that using parcel-level land-use maps [45], we employed the POI-based mixed-use indices based on the Hill numbers [46-49] framework to characterize mixed-land use, following Yue et al.'s POIbased mixed-use strategy [50]. Hill numbers are commonly used to quantify species diversity in ecology and biogeography. They can achieve the measurements of multifaceted diversity of land use by calculating

$$
{ }^{q} D=\left(\sum_{i=1}^{s} p_{i}^{q}\right)^{1 /(1-q)},
$$

where $D$ is the diversity of land use and $q$ is the order of diversity. $s$ is the number of POIs categories present in a TAZ. $p_{i}$ represents the proportion of the $i$ th categories to the total number of POIs within a TAZ. When $q=0,1$, and 2 , the equation changes to three different ways of measure, namely, richness, Shannon entropy, and the Simpson index.

We assessed the public transport environment by distance-based accessibility, service coverage rate, and the number of stations. The index of distance to transit is described by the route distance from the centroid of the TAZ to the nearest bus stop or metro station [42]. We set up buffer zones with different radii for the bus stop and metro station and obtained the service area where the overlap part between the TAZ and the buffer zones is. Then, the service coverage rate within different radii was computed by the ratio of the service area to the total area of the TAZ. Furthermore, distance to expressways, distance to main roads, and distance to minor roads are computed in this study to measure the degree of convenience to get a taxi from the street environment dimension. It should be noted that although the density of road $[27,38,51,52]$ is commonly used to measure the street environment, this index cannot accurately reflect the opportunity to get a taxi in the TAZ-based spatial unit. We found that some TAZs had a road density of zero in our trial computation, even though adjacent roads to these TAZs were available. This was possibly due to the roads always being processed as TAZ boundaries.
We delineated the built environment features as comprehensively as possible. However, the overlap of some dimensions and multiple measurements of the same attribute of the built environment $[42,53]$ created inevitable multicollinearity problems among variables. Therefore, a variance inflation factor (VIF) procedure was tested to diagnose the potential multicollinearity among the regressors, as shown in Table 3. Pearson's correlation coefficients were also used to reflect the linear association of two variables, as illustrated in Figure 5. We can see that the most serious collinearity problem exists between indicators related to land mix. Meanwhile, the correlation between these indicators is also high.

\section{Method}

Given the multicollinearity and high-dimension problems, we utilized two penalization-based regression models [54], the LASSO and the Elastic Net (EN), to estimate the coefficients of the built environment. Compared to traditional linear regression models, the penalization-based approach has two outstanding advantages: the interpretability of the selected variables and the stability of a rigid regression estimation. Moreover, we also explored the difference in results between these two models, which is caused by different types of regularization in the penalty terms. At last, the root mean squared error (RMSE) of both models was reported to evaluate their performance.

The LASSO (least absolute shrinkage and selection operator) approach presented by Tibshirani (1996) [55] can select the variable and infer the causal relationship simultaneously through shrinking some trivial estimated coefficients equal to zero. The basic framework of the variable selection minimizes the residual sum of squares subject to the sum of the coefficients' absolute value being less than a constant. The LASSO estimator $\widehat{\beta}[54]$ can be represented by the following Lagrangian form:

$$
L(\beta, \lambda)=\min _{\beta \in \mathfrak{R}^{p}}\left\{\frac{1}{N}\left\|y-X \beta^{T}\right\|_{2}^{2}+\lambda\|\beta\|_{1}\right\},
$$

where equation (4) is the $L_{1}$ norm penalty which is not differentiable at zero. The tuning parameter $\lambda \geq 0$, also known as the punishment coefficient, is used to balance the empirical error and the sparsity of the model parameter. When the parameter $\lambda=0$, the method turns to the general linear regression model:

$$
\beta_{1}=\sum_{j=1}^{p} \beta_{j}
$$

Elastic Net [56] is an extension of LASSO by adding a quadratic part to the penalty, which uses a combination of LASSO and Ridge regression methods. The objective function of Elastic Net is defined by

$$
L\left(\beta, \lambda_{1}, \lambda_{2}\right)=\min _{\beta \in \mathfrak{R}^{p}}\left\{\frac{1}{N}\left\|y-X \beta^{T}\right\|_{2}^{2}+\lambda_{1}\|\beta\|_{1}+\lambda_{2}\|\beta\|_{2}^{2}\right\},
$$


TABLE 2: Variable description and descriptive statistics of built environment.

\begin{tabular}{|c|c|c|c|c|c|c|c|}
\hline Dimensions & Variables & Variable description & Mean & Max. & Min. & SD & VIF \\
\hline \multirow[b]{2}{*}{ Location } & $\begin{array}{l}\text { Distance to the city center } \\
\text { (D_lc) }\end{array}$ & $\begin{array}{l}\text { The Euclidian distance from the centroid of } \\
\text { each TAZ to Bell Tower }(\mathrm{km})\end{array}$ & 6.501 & 14.633 & 0.259 & 3.325 & 2.835 \\
\hline & $\begin{array}{l}\text { Distance to the nearest local } \\
\text { center (D_nlc) }\end{array}$ & $\begin{array}{l}\text { The Euclidian distance from the centroid of } \\
\text { each TAZ to the nearest regional CBD }(\mathrm{km})\end{array}$ & 2.315 & 7.734 & 0.127 & 1.366 & 1.499 \\
\hline \multirow{3}{*}{ Land mix } & Richness (R) & $\begin{array}{l}\text { The number of different land-use categories } \\
\text { present in a TAZ }\end{array}$ & 14.567 & 19.000 & 0.000 & 3.828 & 6.674 \\
\hline & Shannon entropy (Sh_en) & $\begin{array}{l}\text { "It reflects the amount of order in both POIs } \\
\text { categories and the number of POIs" (Yue et al., } \\
\text { 2016. pp.9) }\end{array}$ & 8.569 & 12.774 & 0.000 & 2.226 & 46.705 \\
\hline & Simpson index $(\mathrm{Si})$ & $\begin{array}{l}\text { It presents the evenness or concentration of } \\
\text { POIs in a TAZ }\end{array}$ & 6.549 & 10.656 & 0.000 & 1.944 & 28.560 \\
\hline \multirow{6}{*}{$\begin{array}{l}\text { Public } \\
\text { transportation }\end{array}$} & Bus accessibility (B_acc) & $\begin{array}{l}\text { The route distance from the centroid of the } \\
\text { TAZ to the nearest bus stop }(\mathrm{km})\end{array}$ & 0.347 & 1.836 & 0.010 & 0.236 & 3.676 \\
\hline & Transit accessibility (Tr_acc) & $\begin{array}{l}\text { The route distance from the centroid of the } \\
\text { TAZ to the nearest metro station }(\mathrm{km})\end{array}$ & 1.524 & 6.532 & 0.129 & 1.129 & 2.734 \\
\hline & $\begin{array}{l}\text { Coverage rate of bus stop within } \\
\text { a radius of } 300 \mathrm{~m} \text { (cr_b_300) }\end{array}$ & $\begin{array}{l}\text { The ratio of bus stop service area within a } \\
\text { radius of } 300 \mathrm{~m} \text { to the total area of the TAZ }\end{array}$ & 0.636 & 1.000 & 0.000 & 0.294 & 3.811 \\
\hline & $\begin{array}{l}\text { Coverage rate of bus stop within } \\
\text { a radius of } 500 \mathrm{~m} \text { (cr_b_500) }\end{array}$ & $\begin{array}{l}\text { The ratio of bus stop service area within a } \\
\text { radius of } 500 \mathrm{~m} \text { to the total area of the TAZ }\end{array}$ & 0.870 & 1.000 & 0.000 & 0.253 & 5.750 \\
\hline & $\begin{array}{l}\text { Coverage rate of metro station } \\
\text { within a radius of } 800 \mathrm{~m} \\
\left(\mathrm{cr} \_\mathrm{m} \_800\right)\end{array}$ & $\begin{array}{l}\text { The ratio of metro station service area within a } \\
\text { radius of } 800 \mathrm{~m} \text { to the total area of the TAZ }\end{array}$ & 0.318 & 1.000 & 0.000 & 0.406 & 1.988 \\
\hline & Number of bus routes (N_br) & $\begin{array}{c}\text { The number of bus routes that pass through } \\
\text { the TAZ }\end{array}$ & 9.47 & 91.00 & 0.00 & 13.11 & 1.227 \\
\hline \multirow{3}{*}{ Street design } & $\begin{array}{l}\text { Distance to the nearest minor } \\
\text { road (D_nmir) }\end{array}$ & $\begin{array}{l}\text { Euclidian distance from the centroid of each } \\
\text { TAZ to the nearest minor road }(\mathrm{km})\end{array}$ & 0.414 & 2.530 & 0.000 & 0.383 & 1.240 \\
\hline & $\begin{array}{l}\text { Distance to the nearest main } \\
\text { road (D_nmar) }\end{array}$ & $\begin{array}{l}\text { Euclidian distance from the centroid of each } \\
\text { TAZ to the nearest main road }(\mathrm{km})\end{array}$ & 0.372 & 2.979 & 0.000 & 0.336 & 1.512 \\
\hline & $\begin{array}{l}\text { Distance to the nearest } \\
\text { expressway (D_nexpw) }\end{array}$ & $\begin{array}{l}\text { Euclidian distance from the centroid of each } \\
\text { TAZ to the nearest expressway }(\mathrm{km})\end{array}$ & 1.141 & 4.100 & 0.008 & 0.927 & 1.474 \\
\hline
\end{tabular}

TABLE 3: Regression results of LASSO and Elastic Net models.

\begin{tabular}{|c|c|c|c|}
\hline Dimensions & Variables & LASSO & Elastic Net \\
\hline \multirow{5}{*}{ Location } & RMSE & 0.240248 & 0.239898 \\
\hline & Constant term & 0.241769 & 0.259710 \\
\hline & Number of nonzero parameters & 6 & 8 \\
\hline & Distance to the city center & 0 & 0 \\
\hline & Distance to the nearest local center & -0.016721 & -0.043576 \\
\hline \multirow{3}{*}{ Land mix } & Richness & -0.091567 & -0.081240 \\
\hline & Shannon entropy & 0 & 0 \\
\hline & Simpson index & 0 & 0 \\
\hline \multirow{6}{*}{ Public transportation } & Bus accessibility & 0 & 0 \\
\hline & Transit accessibility & 0 & 0 \\
\hline & Coverage rate of bus stop within a radius of $300 \mathrm{~m}$ & -0.035096 & -0.034070 \\
\hline & Coverage rate of bus stop within a radius of $500 \mathrm{~m}$ & 0 & -0.013624 \\
\hline & Coverage rate of metro station within a radius of $800 \mathrm{~m}$ & -0.030505 & -0.031962 \\
\hline & Number of bus routes & 0 & -0.000423 \\
\hline \multirow{3}{*}{ Road design } & Distance to the nearest minor road & 0 & 0 \\
\hline & Distance to the nearest main road & 0.022341 & 0.047424 \\
\hline & Distance to the nearest expressway & 0.138179 & 0.121271 \\
\hline
\end{tabular}

where equation (6) is the $L_{2}$ norm penalty. Elastic Net (EN) is a hybrid model and works between LASSO and Ridge regression by setting two tuning parameters $\lambda_{1}, \lambda_{2} \geq 0$. Let $\alpha=\lambda_{1}+\lambda_{2}$ and $L_{1-\text { ratio }}=\lambda_{1} /\left(\lambda_{1}+\lambda_{2}\right)$. $L_{1}$ ratio can be determined by minimizing the RMSE, as shown in Figure 6:

$$
\beta_{2}^{2}=\sum_{j=1}^{p} \beta_{j}^{2} .
$$

All feature variable values were preprocessed by using the $Z$-score standardization and centered methods. The 


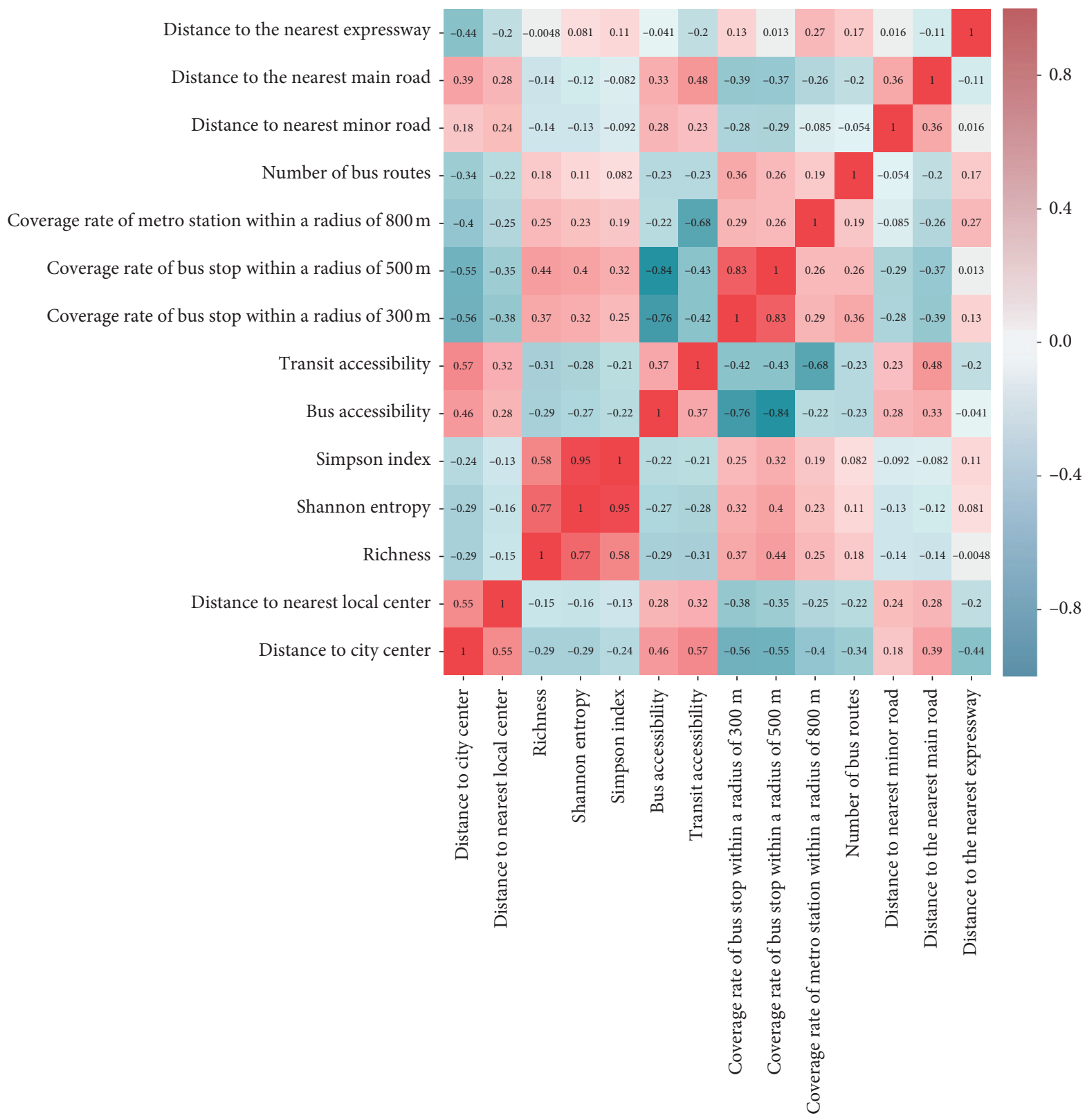

Figure 5: Correlation analysis of variables based on Pearson's correlation coefficient.

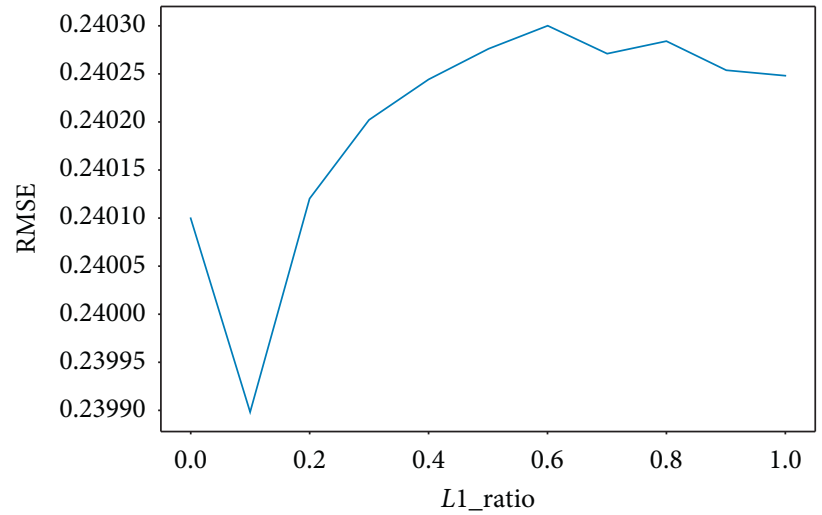

FIGURE 6: Variation of RMSE with $L_{1}$-ratio. 
regularization parameters of these two regression models were estimated by performing the 10 -fold cross validation (CV) [57] due to its outperformance of AIC, BIC, and 5-fold $\mathrm{CV}$ in our study. The nonzero regression coefficients and their corresponding feature variables in LASSO and Elastic Net are listed in Table 3.

\section{Discussion}

5.1. Regression Coefficients. It can be seen from Table 3 that different numbers of features were selected by different models. The feature variables corresponding to the nonzero regression coefficients in the Elastic Net model are two more than those in the LASSO model, which confirmed the sparsity of LASSO results caused by the $L_{1}$ norm penalty [57]. Figure 7 shows the different regression paths of coefficients under different penalty terms. The horizontal axis represents tuning parameters and the vertical axis represents the coefficient of variation.

As shown in Table 3, the RMSE of the Elastic Net is slightly lower than that of LASSO, which means the Elastic Net model performed better in this study. Therefore, further analysis will be based on the results of the Elastic Net. Compared to the Elastic Net, the regression coefficients of coverage rate of bus stop within a radius of $500 \mathrm{~m}$ and number of bus routes were shrunk to zero by LASSO. Meanwhile the influence degree and direction of other features estimated by Elastic Net were consistent with the results of LASSO. This is due to the same mechanism of parameter estimation between these two regression models. Overall, four dimensions of the built environment had an influence on the relative variation (RV) of taxi ridership in varying degrees. Eight out of 14 variables appear to have significant influences on relative variations (RVs). Some variables of location, land mix, and public transportation dimensions have negative effects on the $\mathrm{RV}$; they are distance to the nearest local center, richness, coverage rate of bus stop within a radius of $300 \mathrm{~m}$, coverage rate of bus stop within a radius of $500 \mathrm{~m}$, coverage rate of the metro station within a radius of $800 \mathrm{~m}$, and number of bus routes. Meanwhile features of distance to the nearest main road and distance to the nearest expressway in the road design dimension have positive influences on the RV.

Specifically, for variables pertaining to public transportation, the $\mathrm{RV}$ is primarily influenced by the coverage rate of the bus stop within a radius of $300 \mathrm{~m}$, secondarily by the coverage rate of the metro station within a radius of $800 \mathrm{~m}$, and thirdly by the coverage rate of the bus stop within a radius of $500 \mathrm{~m}$. These variables are all inversely related to RV, which means that relative variations in taxi ridership are generally greater in locations that have inconvenient public transportation. This is reasonable because more people have to choose a taxi when their private cars are restricted on road in the environment of inconvenient public transportation. It should be noted that the rail transit network in Xi' an has not formed yet and only four subway lines are in operation. Therefore, the degree of urban rail transit influence will be far greater than the results of current analysis due to its overwhelming advantage in traffic capacity. Note that two highly correlated variables $c r \_b \_300$ and $c r \_b \_500$ are

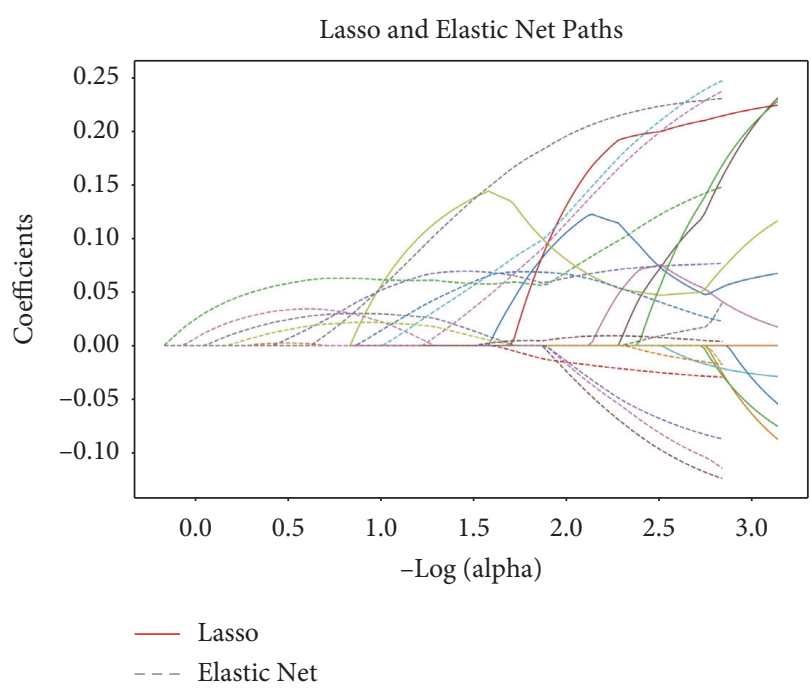

Figure 7: Coefficient paths of LASSO and Elastic Net regression models (let $\alpha=\lambda$ in LASSO and $\alpha=\lambda_{1}+\lambda_{2}$ in Elastic Net).

permitted into the Elastic Net regression model, but the latter was insignificant in the LASSO model. This makes sense because these two indicators reflect different levels of public transportation service. Regions with a higher level of public transportation service have a stronger ability of vehicle restriction policy response. For the land-use dimension, both two models kept the richness. From the location perspective, distance to the nearest local center has a significant influence effect and distance to city center does not. This suggests that a convenient living environment can mitigate the traffic contradiction caused by the LPR policy. More concretely, to reduce the negative externalities of the LPR policy, improving the service level of the public transport network is the primary mean of transferring the travel demand restricted by the LPR policy to public transit. In linear regression, a higher value of the absolute magnitude indicates a greater marginal effect. Therefore, for the policymaker and transportation planner, the priority is to increase the basic requirements for the service coverage of public transportation. Then the walking distance to the bus stop is considered to be further shortened by increasing the bus stop density, that is, the coverage rate of the bus stop within the radius of $300 \mathrm{~m}$. Besides, planning more urban subcenters to improve the convenience of the living environment is a long-term solution.

The above conclusions are not only consistent with previous findings $[9,10]$ but improve and broaden the existing literature from the research perspective and data type. Although the vehicle plate recognition data [10] is more accurate and has a higher coverage rate than personal trip surveys $[26,58]$ in evaluating road network performance, the data collection spots are limited to the intersections equipped with detectors. Compared with this data, the floating car data in this study can be theoretically used to obtain traffic conditions at any time and any location on a road network. Therefore, we conducted a finer-grained spatial analysis in travel demand transfer based on taxi GPS data, which has not yet been reported to the best of our knowledge. 


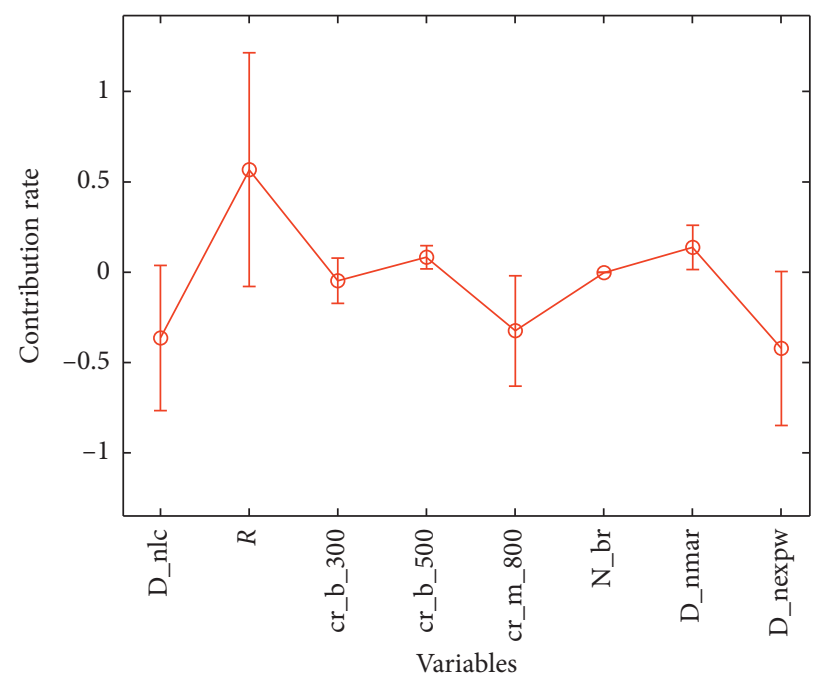

Figure 8: Contribution rate of different built environment variables.

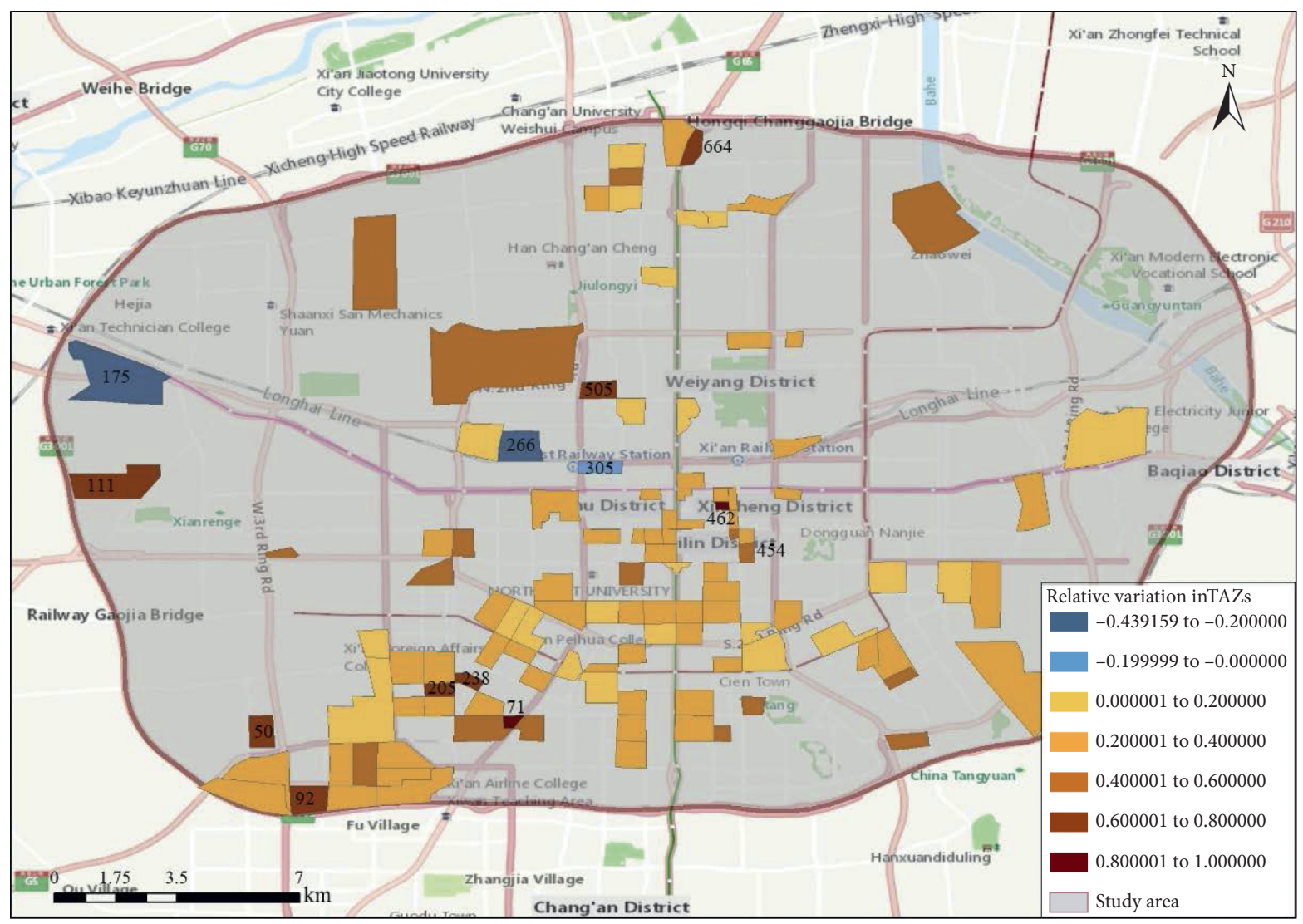

FIgURE 9: Spatial distribution of relative variation in taxi ridership on Friday.

5.2. Contribution of Different Variables. To investigate the relative impact of different variables, we analyzed the different contributions of selected built environment variables to the relative variation of taxi ridership. For a given variable, its contributions differ from the TAZ. Hence, we compute the mean contribution and its associated standard deviation for each built environment variable. The results are illustrated with the error bar in Figure 8. The circle represents the average contribution level of its corresponding variable and the length of the bar represents its volatility of contribution in different regions. The longer the bar is, the more dispersed contribution of a variable is. We can see that features pertaining to public transportation all have a stable contribution as a whole. This suggested that improving the 
TABLE 4: Significantly influenced regions ordered by the variation in taxi ridership.

\begin{tabular}{|c|c|c|c|c|c|c|}
\hline \multirow{2}{*}{ Tendency } & \multirow{2}{*}{ No. of TAZs } & \multicolumn{2}{|c|}{ Relative variation } & \multicolumn{3}{|c|}{ Important indexes of the built environment } \\
\hline & & Value & Rank & $c r \_b \_300$ & $c r \_b \_500$ & cr_m_800 \\
\hline \multirow{10}{*}{ Increase } & 71 & 0.9783 & 1 & 0.5125 & 1.0000 & 0.0000 \\
\hline & 462 & 0.8750 & 2 & 0.4289 & 1 & 0.9998 \\
\hline & 111 & 0.7857 & 3 & 0.0000 & 0.0000 & 0.0000 \\
\hline & 50 & 0.6654 & 4 & 0.0303 & 0.1838 & 0.0000 \\
\hline & 238 & 0.6316 & 5 & 0.9154 & 1.0000 & 0.0000 \\
\hline & 205 & 0.6145 & 6 & 0.7305 & 1.0000 & 0.0000 \\
\hline & 505 & 0.6139 & 7 & 0.5770 & 1.0000 & 0.0000 \\
\hline & 92 & 0.6098 & 8 & 0.4196 & 0.8092 & 0.0000 \\
\hline & 664 & 0.6029 & 9 & 0.1377 & 0.5777 & 0.9654 \\
\hline & 454 & 0.5550 & 10 & 1 & 1 & 0 \\
\hline \multirow{3}{*}{ Decrease } & 175 & -0.4392 & 1 & 0.1704 & 0.3187 & 0.3119 \\
\hline & 266 & -0.3946 & 2 & 0.6176 & 0.9991 & 0.0000 \\
\hline & 305 & -0.1596 & 3 & 0.9442 & 1.0000 & 0.6630 \\
\hline
\end{tabular}

Note. $c r \_b \_300$ is the abbreviation for the coverage rate of bus stop within a radius of 300 meters; $c r \_m \_800$ is the abbreviation for the coverage rate of the metro station within a radius of 800 meters.

level of public transportation service will be effective in any region. However, the contrition rate of richness with the longest bar has large differences among regions. Therefore, further research about specific types of land use will be necessary before the related strategies can be proposed.

5.3. Significantly Influenced Regions. Regions with great variations in taxi ridership are significantly influenced by the vehicle restriction policy and need more effective improvement measures to meet the transferred travel demand. Combined with Wilcoxon's signed-rank test, a nonparametric counterpart of the paired $t$-test, we further scrutinized the regions with statistically significant differences, as shown in Figure 9. We screened out the top ten increased TAZs and the top three (all) decreased TAZs with a statistically significant difference as the priority areas for improvement. The number of these selected 13 TAZs and their corresponding built environment parameters are listed in Table 4. The rank is derived based on the absolute value of the relative variation. Overall, taxi ridership throughout the main city presented a growth trend. This suggests that the vehicle restriction policy imposed tremendous pressure on the taxi industry, which is positioned as an auxiliary public transport mode. The only three decreased areas were those that generally have the high value of selected built environment variables, which means that public transportation handled the transferred travel demand from the individual travel mode.

\section{Conclusions}

Given the intrinsic relationship between taxis and public transport, this study stands by the position of the citywide taxi services to rethink the shortcomings of public transportation service under the vehicle restriction policy. The two types of penalization-based regression models, the LASSO and Elastic Net regression models, were employed to explore how the built environment influences the mode shift of commuting travel, using taxi GPS data covering the periods before and after the ODPW policy implementation in Xi'an.

The contrastive analysis demonstrates that the vehicle restriction policy indeed triggered an overwhelming amount of restricted private car travel demand transferred to a taxi, which was supposed to be shared by public transportation. The regression analysis shows that the relative variation is most strongly related to distance to the nearest local center and secondarily to coverage rate of the bus stop within a radius of $300 \mathrm{~m}$. These findings highlight the vital role of improving public transport services in implementing vehicle restriction policies, which is consistent with the results of previous studies $[9,12]$. Furthermore, the marginal benefit and contribution rate of selected variables can provide the implications to the regional differences in the effectiveness of the strategies.

Besides, it is confirmed that ineffective enforcement also contributed to the unsatisfactory results of LPR [18]. Therefore, a set of reasonable penalty mechanisms should be established to strengthen the effectiveness of the vehicle restriction policy. For instance, illegal travel was captured by surveillance and punished by driving offense points and traffic violation fines. However, for travelers with a relatively high-income level, the deterrent effect of this penalty measure will be offset by higher time value [10]. Thus, it is necessary to link to the individual credit system to restrain illegal travel behavior.

In the future, a growing number of cities like Xi' an could adopt the LPR policy to rein in automobile use and will have to experience the adaptive phase of implementing this policy. Therefore, the findings of this study could help policy-makers predict the possible influence of the LPR policy on urban wide travel demand and refine the policy of travel demand management. However, there also exist a few limitations in this study. First, the other types of travel demand data, such as AFC data, bus IC card data, and ridesourcing data [59], should be used for data fusion analysis to understand the mode transfer under the LPR policy more precisely. Second, as previously mentioned, population and 
employment in the demographics should be introduced into the regression model in further research.

\section{Data Availability}

The dataset used in this study cannot be made available for public due to the agreement of a contract.

\section{Conflicts of Interest}

The authors declare that there are no conflicts of interest regarding the publication of this paper.

\section{Acknowledgments}

This work was sponsored in part by the National Natural Science Foundation of China under Grant 71901040 and the Natural Science Foundation of Shaanxi Province, China under Grants 2019JQ-242 and 2019JQ-442.

\section{References}

[1] H. Yang, M. Ma, J. R. Thompson, and R. J. Flower, "Waste management, informal recycling, environmental pollution and public health," Journal of Epidemiology and Community Health, vol. 72, no. 3, pp. 237-243, 2018.

[2] J. Wang, Q. Wu, J. Liu et al., "Vehicle emission and atmospheric pollution in China: problems, progress, and prospects," PeerJ, vol. 7, Article ID e6932, 2019.

[3] MOE Protection, Annual Report of Automobile Air Pollution in China, Ministry of Environment Protection, Beijing, China, 2016.

[4] R. Kitamura, S. Fujii, and E. I. Pas, “Time-use data, analysis and modeling: toward the next generation of transportation planning methodologies," Transport Policy, vol. 4, no. 4, pp. 225-235, 1997.

[5] S. Feng and Q. Li, "Car Ownership Control in Chinese Mega Cities: Shanghai, Beijing and Guangzhou," Journeys, LTA Academy Singapore), Singapore, 2013.

[6] M. Percoco, "Is road pricing effective in abating pollution? Evidence from Milan," Transportation Research Part D: Transport and Environment, vol. 25, pp. 112-118, 2013.

[7] D. Hidalgo, "Structural change in Bogota's transportation systems: public and non-motorized transportation priority and private car restrictions," in Proceedings of the Urban Public Transportation System: Ensuring Sustainability through Mass Transit, pp. 26-36, Alexandria, Virginia, USA, 2004.

[8] H. C. Goddard, "Optimal restrictions on vehicle use for urban sustainability for Mexico city," International Journal of Environment and Pollution, vol. 7, no. 3, pp. 357-374, 1997.

[9] D. Mohan, G. Tiwari, R. Goel, and P. Lahkar, "Evaluation of odd-even day traffic restriction experiments in Delhi, India," Transportation Research Record: Journal of the Transportation Research Board, vol. 2627, no. 1, pp. 9-16, 2017.

[10] Z. Liu, R. Li, X. Wang, and P. Shang, "Effects of vehicle restriction policies: analysis using license plate recognition data in Langfang, China," Transportation Research Part A: Policy and Practice, vol. 118, pp. 89-103, 2018.

[11] J. Xu and J. Ma, "Economic analysis of driving restriction by car tail number," in World Automation Congress, vol. 2012, , pp. 1-4, IEEE, 2012.
[12] X. Lu, "Effectiveness of government enforcement in driving restrictions: a case in Beijing, China," Environmental Economics and Policy Studies, vol. 18, no. 1, pp. 63-92, 2016.

[13] R. Li and M. Guo, "Effects of odd-even traffic restriction on travel speed and traffic volume: evidence from Beijing Olympic Games," Journal of Traffic and Transportation Engineering (English Edition), vol. 3, no. 1, pp. 71-81, 2016.

[14] V. B. Viard and S. Fu, "The effect of Beijing's driving restrictions on pollution and economic activity," Journal of Public Economics, vol. 125, pp. 98-115, 2015.

[15] J. Geng, R. Long, H. Chen, and Q. Li, “Urban residents' response to and evaluation of low-carbon travel policies: evidence from a survey of five eastern cities in China," Journal of Environmental Management, vol. 217, pp. 47-55, 2018.

[16] N. Jia, Y. Zhang, Z. He, and G. Li, "Commuters' acceptance of and behavior reactions to license plate restriction policy: a case study of Tianjin, China," Transportation Research Part D: Transport and Environment, vol. 52, pp. 428-440, 2017.

[17] Y. Nie, "Why is license plate rationing not a good transport policy?” Transportmetrica A: Transport Science, vol. 13, no. 1, pp. 1-23, 2017.

[18] L. de Grange and R. Troncoso, "Impacts of vehicle restrictions on urban transport flows: the case of Santiago, Chile," Transport Policy, vol. 18, no. 6, pp. 862-869, 2011.

[19] G. S. Eskeland and T. Feyzioglu, "Rationing can backfire: the "day without a car" in Mexico city," The World Bank Economic Review, vol. 11, no. 3, pp. 383-408, 1997.

[20] J. Gilliland, M. Holmes, J. D. Irwin, and P. Tucker, "Environmental equity is child's play: mapping public provision of recreation opportunities in urban neighbourhoods," Vulnerable Children and Youth Studies, vol. 1, no. 3, pp. 256-268, 2006.

[21] H. Huo, Q. Zhang, K. He, Z. Yao, and M. Wang, "Vehicle-use intensity in China: current status and future trend," Energy Policy, vol. 43, pp. 6-16, 2012.

[22] P. Klungboonkrong, S. Jaensirisak, and T. Satiennam, "Potential performance of urban land use and transport strategies in reducing greenhouse gas emissions: Khon Kaen case study, Thailand," International Journal of Sustainable Transportation, vol. 11, no. 1, pp. 36-48, 2017.

[23] H. Huang, D. Fu, and W. Qi, "Effect of driving restrictions on air quality in Lanzhou, China: analysis integrated with internet data source," Journal of Cleaner Production, vol. 142, pp. 1013-1020, 2017.

[24] S. Chowdhury, S. Dey, S. N. Tripathi, G. Beig, A. K. Mishra, and S. Sharma, "“Traffic intervention" policy fails to mitigate air pollution in megacity Delhi," Environmental Science \& Policy, vol. 74, pp. 8-13, 2017.

[25] K.-S. Hwang, Y. E. Shin, T.-H. Ko, S. H. Oh, J.-H. Lim, and I.-S. Kim, "Assessing the effects of the vehicle restriction policy: U-do Island in Jeju-Do, Korea," in Proceedings of the Eastern Asia Society for Transportation Studies, p. 25, Istanbul, Turkey, 2011.

[26] L. Wang, J. Xu, and P. Qin, "Will a driving restriction policy reduce car trips?-The case study of Beijing, China," Transportation Research Part A: Policy and Practice, vol. 67, pp. 279-290, 2014.

[27] B. Sun, A. Ermagun, and B. Dan, "Built environmental impacts on commuting mode choice and distance: evidence from Shanghai," Transportation Research Part D: Transport and Environment, vol. 52, pp. 441-453, 2017.

[28] F. Gallego, J.-P. Montero, and C. Salas, "The effect of transport policies on car use: evidence from Latin American cities," Journal of Public Economics, vol. 107, pp. 47-62, 2013. 
[29] C.-Y. C. Lin Lawell, W. Zhang, and V. I. Umanskaya, "The Effects of Driving Restrictions on Air Quality: Theory and Empirical Evidence," Working Paper, University of California at Davis, Davis, CA, USA, 2015.

[30] M. Xu, S. Grant-Muller, and Z. Gao, "Implementation effects and integration evaluation of a selection of transport management measures in Beijing," Case Studies on Transport Policy, vol. 5, no. 4, pp. 604-614, 2017.

[31] E. Guerra and A. Millard-Ball, "Getting around a license-plate ban: behavioral responses to Mexico city's driving restriction," Transportation Research Part D: Transport and Environment, vol. 55, pp. 113-126, 2017.

[32] D. An, X. Tong, K. Liu, and E. H. W. Chan, "Understanding the impact of built environment on metro ridership using open source in Shanghai," Cities, vol. 93, pp. 177-187, 2019.

[33] Y. Zhu, F. Chen, Z. Wang, and J. Deng, "Spatio-temporal analysis of rail station ridership determinants in the built environment," Transportation, vol. 46, no. 6, pp. 2269-2289, 2019.

[34] T. Çetin and K. Yasin Eryigit, "Estimating the effects of entry regulation in the Istanbul taxicab market," Transportation Research Part A: Policy and Practice, vol. 45, no. 6, pp. 476484, 2011

[35] C. Fan, Y. Li, P. Liu et al., "Characteristics of airborne opportunistic pathogenic bacteria during autumn and winter in Xi'an, China," Science of The Total Environment, vol. 672, pp. 834-845, 2019.

[36] Z. Shi, J. Li, L. Huang et al., "Source apportionment of fine particulate matter in China in 2013 using a source-oriented chemical transport model," Science of the Total Environment, vol. 601-602, pp. 1476-1487, 2017.

[37] R. Lu, Y. Li, W. Li et al., "Bacterial community structure in atmospheric particulate matters of different sizes during the haze days in Xi'an, China," Science of the Total Environment, vol. 637-638, pp. 244-252, 2018.

[38] X. Qian and S. V. Ukkusuri, "Spatial variation of the urban taxi ridership using GPS data," Applied Geography, vol. 59, pp. 31-42, 2015.

[39] X. Qian, X. Zhan, and S. V. Ukkusuri, "Characterizing urban dynamics using large scale taxicab data," in Proceedings of Engineering and Applied Sciences Optimization, pp. 17-32, Kos, Greece, 2015.

[40] J. Tang, F. Liu, Y. Wang, and H. Wang, "Uncovering urban human mobility from large scale taxi GPS data," Physica A: Statistical Mechanics and Its Applications, vol. 438, pp. 140153, 2015.

[41] L. Gong, X. Liu, L. Wu, and Y. Liu, "Inferring trip purposes and uncovering travel patterns from taxi trajectory data," Cartography and Geographic Information Science, vol. 43, no. 2, pp. 103-114, 2016.

[42] R. Ewing and R. Cervero, "Travel and the built environment," Journal of the American Planning Association, vol. 76, no. 3, pp. 265-294, 2010.

[43] L. Hu, T. Sun, and L. Wang, "Evolving urban spatial structure and commuting patterns: a case study of Beijing, China," Transportation Research Part D: Transport and Environment, vol. 59, pp. 11-22, 2018.

[44] C. Ding, X. Cao, and P. Næss, “Applying gradient boosting decision trees to examine non-linear effects of the built environment on driving distance in Oslo," Transportation Research Part A: Policy and Practice, vol. 110, pp. 107-117, 2018.

[45] S. Jiang, A. Alves, F. Rodrigues, J. Ferreira Jr., and F. C. Pereira, "Mining point-of-interest data from social networks for urban land use classification and disaggregation," Computers, Environment and Urban Systems, vol. 53, pp. 36-46, 2015.

[46] A. Chao, C.-H. Chiu, and L. Jost, "Unifying species diversity, phylogenetic diversity, functional diversity, and related similarity and differentiation measures through Hill numbers," Annual Review of Ecology, Evolution, and Systematics, vol. 45, no. 1, pp. 297-324, 2014.

[47] L. Jost, "Entropy and Diversity," Oikos, vol. 113, no. 2, pp. 363-375, 2006.

[48] M. O. Hill, "Diversity and evenness: a unifying notation and its consequences," Ecology, vol. 54, no. 2, pp. 427-432, 1973.

[49] R. MacArthur, Patterns of Species Diversity: Biological Review, vol. 40, 1965.

[50] Y. Yue, Y. Zhuang, A. G. O. Yeh, J.-Y. Xie, C.-L. Ma, and Q.-Q. Li, "Measurements of POI-based mixed use and their relationships with neighbourhood vibrancy," International Journal of Geographical Information Science, vol. 31, no. 4, pp. 658-675, 2017.

[51] P. Zhao, "The impact of the built environment on individual workers' commuting behavior in Beijing," International Journal of Sustainable Transportation, vol. 7, no. 5, pp. 389415, 2013.

[52] W. Zhu, C. Ding, and X. Cao, "Built environment effects on fuel consumption of driving to work: insights from on-board diagnostics data of personal vehicles," Transportation Research Part D: Transport and Environment, vol. 67, pp. 565575, 2019.

[53] S. L. Handy, M. G. Boarnet, R. Ewing, and R. E. Killingsworth, "How the built environment affects physical activity," American Journal of Preventive Medicine, vol. 23, no. 2, pp. 64-73, 2002.

[54] A. Belloni, V. Chernozhukov, and C. Hansen, "High-dimensional methods and inference on structural and treatment effects," Journal of Economic Perspectives, vol. 28, no. 2, pp. 29-50, 2014.

[55] R. Tibshirani, "Regression shrinkage and selection via the lasso," Journal of the Royal Statistical Society: Series B (Methodological), vol. 58, no. 1, pp. 267-288, 1996.

[56] H. Zou and T. Hastie, "Regularization and variable selection via the elastic net," Journal of the Royal Statistical Society: Series B (Statistical Methodology), vol. 67, no. 2, pp. 301-320, 2005.

[57] S. Mohebbi, E. Pamukcu, and H. Bozdogan, "A new data adaptive elastic net predictive model using hybridized smoothed covariance estimators with information complexity," Journal of Statistical Computation and Simulation, vol. 89, no. 6, pp. 1060-1089, 2019.

[58] C. Y. Li, S. Y. Sun, and J. F. Guo, "Research on travel behavior changes under vehicle-use-restriction measures during the Olympic games," in Proceedimgs of the ICCTP 2009: Critical Issues in Transportation Systems Planning, Development, and Management, pp. 1-7, Harbin, China, August 2009.

[59] Y. Nie, "How can the taxi industry survive the tide of ridesourcing? Evidence from Shenzhen, China," Transportation Research Part C: Emerging Technologies, vol. 79, pp. 242-256, 2017. 